\title{
INVENTORY, MAPPING, GEOMORPHIC CHARACTERIZATION, AND VALIDATION OF DEEP-SETATED LANDSLIDES USING SKY-VIEW FACTOR VISUALIZATION: NORTHERN, CENTRAL, AND SOUTHERN TAIWAN
}

\author{
C. F. Lee ${ }^{1, *}$, W. K. Huang ${ }^{1}$, C. L. Chiu ${ }^{2}$, C. C. Chi $^{2}$ \\ ${ }^{1}$ Disaster Prevention Technology Research Center, Sinotech Engineering Consultants, INC., Taipei, Taiwan, (R.O.C.) - (cflee, \\ wuangwk)@sinotech.org.tw \\ ${ }^{2}$ Environmental \& Engineering Geology Division, Central Geological Survey, MOEA., New Taipei City, Taiwan, (R.O.C.) - (chiucl, \\ chitc)@moeacgs.gov.tw
}

KEY WORDS: Deep-seated landslide, LiDAR DEMs, Sky-view factor, Landslide micro-topography interpretation, Landslide susceptibility

\begin{abstract}
:
Extreme rainfall with long-term period plays a principal role in triggering deep-seated landslide around the mountainous area. A well-known typhoon Morakot, the most destructive event occurred in August 2009, battered southern Taiwan and caused severe casualties in Siaolin Village. To reduce the damage and to prevent loss of life resulting from the catastrophic landslide, this study adopted high-resolution topographic data which extracted from airborne LiDAR scanning to interpret both recent and ancient deepseated landslides in northern, central, and southern Taiwan. Firstly, a relief visualization technique called sky-view factor was utilized to generate the quasi-3D map by overlapping slope gradient, and multiple direction hillshading maps, allowing one to interpret manually detailed landslide topography and assess the hazard potential. The study area of the on-going project covers an area of $17,000 \mathrm{~km}^{2}$. This study recognized main scarp and landslide body in polygon pattern by landslide micro-topography interpretation; it showed more than 700 deep-seated landslides were mapped and located on Central Range and Western foothills in Taiwan. The spatial distribution of deep-seated landslide relates highly to the regional strike of formation, daylight at the toe, riverbank erosion, and drainage density. Additionally, the detrimental geomorphic and topographic features are extracted to evaluate the landslide activity in the future. For a landslide zonation which characterized with sharp scarp and greater deformation rate, it usually may represent higher failure susceptibility. This work also uses the 3-D terrain model created by drone photography and geomorphometric analysis to validate the expert-based landslide susceptibility. Furthermore, the result of the study will contribute updating the national-wide environmental geologic map and provide competent authority to make decisions reducing the geohazard risk.
\end{abstract}

\section{INTRODUTION}

In a subtropical and tropical area of western Pacific, the rainfall of typhoon is much higher, resulting in many sediment-related disasters. Deep-seated landslide, which characterized by largescale influence area and sediment volume, can be considered as a critical natural disaster in the mountainous area around the world. To identify the landslide-prone areas, several landslide mapping approaches by automatic and manually identifications were developed in the decades (Booth, 2009; Martha, 2010; Van Den Eeckhaut, 2013; Nonomura, 2013; Petschko, 2016;). Different remote sensing techniques such as LiDAR (Light Detection and Ranging), InSAR, and UAV survey are also applied to detect regional landslide in advanced. Concerning deep-seated landslide, the location is usually covered with dense forest in subtropical zone and difficult to map the exact terrain boundary of landslide on aerial or satellite image. Identification of deep-seated landslide pattern suggests that high-resolution digital terrain model (after removing the vegetation on the ground) is one of the best topographical data. Several studies have shown that landform enhancement on the shading relief map is a practical approach for micro-relief structures of mapping slope-land related natural hazards (Yokoyama, 2002; Razak, 2011; Zakšek, 2011; Mayoral, 2017). For enhancing surface features in the landslide-prone area, the landslide micro-topography interpretation is performed by using the combination of analytical hill-shading in multiple directions, slope gradient, colour cast, and openness (positive and negative) visualizations. The application of three-dimensional visualization facilitates manual interpretation and digitalizing precision in comparison with using a single relief map.

Typhoons and monsoons bring large amounts of rainfall which is estimated from $2,500 \mathrm{~mm}$ to more than $3,000 \mathrm{~mm}$ around mountainous areas annually in Taiwan. Besides, regional landslide and debris flow disaster are influenced by frequent earthquake and storm hitting (3-4 typhoons strike Taiwan every year). This external natural process helps to induce an unstable condition for hillslope and even triggering the deep-seated catastrophic landslide in the mountainous area (i.e., a wellknown Siaolin Village landslide disaster during Typhoon Morakot, 2009). It drives us to the question whether all the landslide-prone sites could be recognized and investigated, so the regional mapping of the deep-seated landslide is necessary for disaster prevention and management.

This on-going project supported by Central Geological Survey (CGS), MOEA divides Taiwan into four main regions covering the northern (2015), southern (2016), central (2017), and eastern (2018) Taiwan. This paper focuses on the western part of Taiwan, which contains 137 map sheets with 1/25,000 scale

\footnotetext{
* Corresponding author
} 
generated by airborne LiDAR scanning during 2010 and 2015 . The primary purpose of this project includes two aspects: establishing national-wide deep-stead landslide inventory and assess reactivation of old landslides. Both expert-based interpretation and on-site survey are the main analytical process for landslide mapping and susceptibility classification. A generation procedure of sky-view factor relief map will be first developed to replace the traditional 8-directions hill-shading on high-resolution DTMs. Moreover, the feature of the deep-seated landslide is extracted to identify the pattern and boundary. Detailed expert criteria are also discussed to assess the possible reactivation of the old landslides. This visualization result can provide the fundamental data for updating the environmental geological map and assist deciding the proper site with high priority for establishing long-term monitoring system.

\section{STUDY AREA}

Taiwan is located in the western Pacific Ocean, at the convergent plate boundary zone of Philippine Sea plate and Eurasian plate, causing hundreds of faults and folds due to tectonic activity (Fig. 1(a); Lee, 2016). The topography in the study area (northern, central, and southern Taiwan) consisted mostly of the basin, plain, volcano, plateau, and mountain region (Fig. 1(b)). The coastal plain gains the height of Central Range at an elevation between 10 (plain) to 3,952 m (Central Range). According to the official geological map, the geological setting of the study area contains sedimentary rock, pyrogenetic rock, metamorphic rock, slate, volcanic breccia, and conglomerate. Rainfall statistics in this region shows the annual averaged rainfall and rainfall day are 2,500 $\mathrm{mm}$ and 120 days, respectively (Central Weather Bureau).

Due to the high population density (647 population $/ \mathrm{km}^{2}$ ) and the frequent occurrence of multiple natural disasters, World Bank reported that Taiwan is one of the most high-risk countries around the world (Dilley, 2005). So far as extreme rainfall event is concerned, 3-4 typhoons hit Taiwan averagely and wreak their damage around the track path. The last one brought with severe regional landslide hazard was Typhoon Soudelor, which struck northern Taiwan in August 2015 and triggered several landslides and debris flow disaster in New Taipei City and caused seven deaths, five missing, and 402 injured.

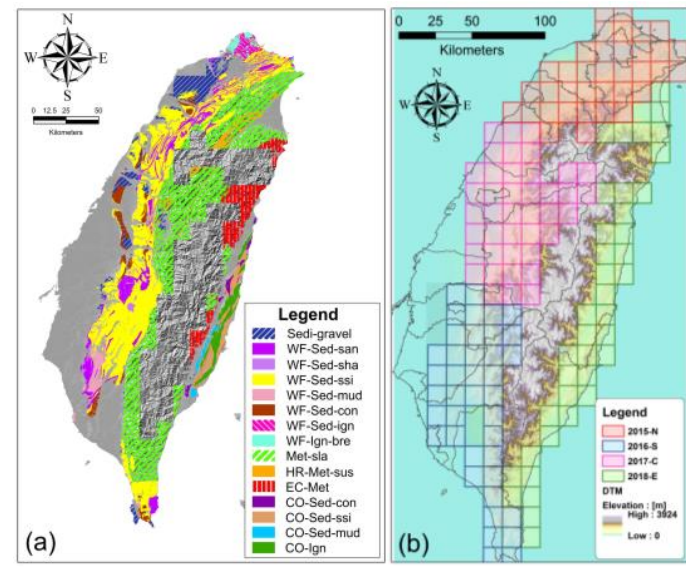

Figure 1. (a) Geological settings in Taiwan (geologic legend: Sedi: sedimentary rock; WF: western foothills; Met: metamorphic rock; HR: Hsuehshan range; EC: Eastern flank of central range; CO: Coastal range; san: sandstone; sha: shale; ssi: sandstone-shale interbedded; nud: mudstone; con: conglomerate; ign: igneous rock; bre: breccia; sla: slate; sus: submetamorphism snadstone) and (b) study area in northern

(2015), southern (2016), and central (2017) Taiwan

\section{MATERIAL AND METHODOLOGY}

\subsection{DEMs production from Airborne LiDAR}

After the sediment-related disaster of Typhoon Morakot, Central Geological Survey launched the project, which was entitled: "Investigation and analysis for the geologically sensitive area in national preservation domain program" from 2009 to 2015. This national program adopted the wide-range airborne LiDAR technique to generate DEMs of $1 \mathrm{~m}$ spatial resolution in a metropolitan and mountainous area covering the whole Taiwan. For the demand of the application, the corresponding mean cloud density in alpine zone is at least 2 points $/ \mathrm{m}^{2}$. All the produced LiDAR derivatives such as DSM and DEM are separated into individual map sheets with 1:5000 scales for regional geohazard assessment (one 1/25,000 frame contains twenty-five 1/5,000 map). Fig. 2 shows the workflow of this study; it includes three parts: data acquisition, data production, and referenced map overlay. Beyond the dataset of DEMs mentioned above, environmental geological map, disaster potential map, orthophoto image (i.e., Google Earth and drone image), and landslide inventory are also included. Finally, the result of work will be involved to update the inventory and landslide susceptibility.

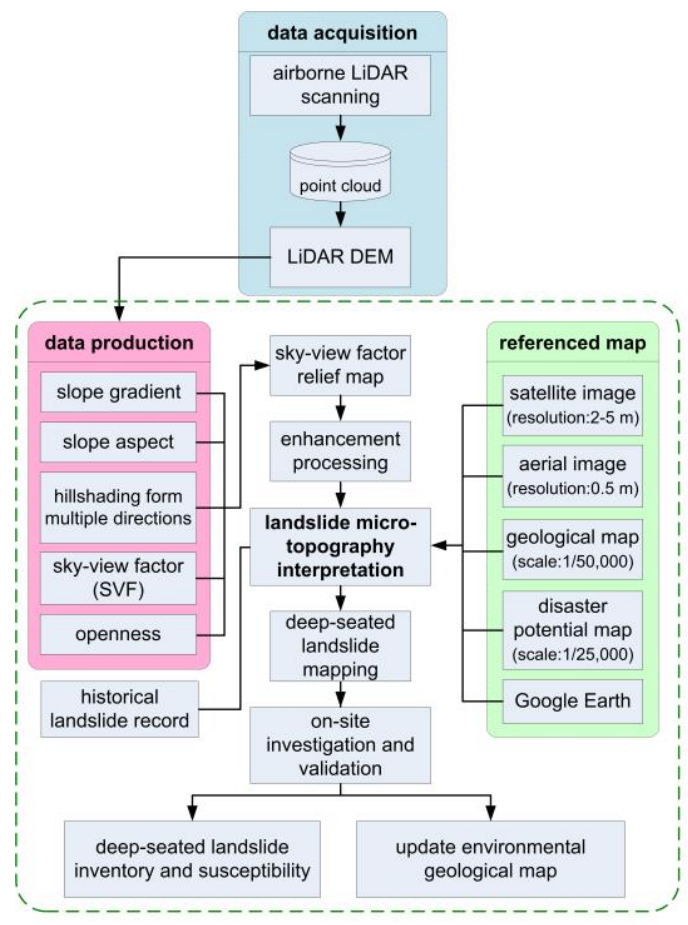

Figure 2. workflow of the study

\subsection{SVF relief map}

Conceptually similar to topographic openness, diffuse illumination can be adopted in relief maps to address the shadowing effect caused by a light source from a single direction (Zakšek, 2011). The SVF (sky view factor) can be regarded as a virtual light source within a hemisphere situated at the center of the point of illumination. The definition of SVF follows the assumptions: (1) uniform light throughout the 
hemisphere, (2) no other sources of light, and (3) disregard of any changes in the curvature of the Earth within a $10 \mathrm{~km}$ radius. Fig. 3 illustrates the procedure used in the compilation of the SVF relief map, which first involved compiling a slope map and then an SVF map by using the LiDAR DEMs. In layering the maps together, changes in elevation are enhanced, and noise is removed as needed. The result is a monochrome SVF relief map, which is then combined with a color elevation map to produce a colored SVF relief map. Fig. 3 demonstrates relief maps of the landslide area before the disaster, which was compiled using the proposed approach. The steeper terrain on SVF relief map is displayed in darker tones, whereas gentler slopes are presented in lighter tones. The flat river terrace or alluvial fan even shows a micro-drainage system, and the bulging mountain ridgelines (lighter tones) and recessed ravines (darker tones) are also more clearly discernible. The using of SVF relief map instead of hillshading in 8 directions will advantage geologic experts to interpret fundamental characteristic of the landslide (scarp, ridge, and streamline), and reduce the analysis time of mapping by utilizing an only single relief map.

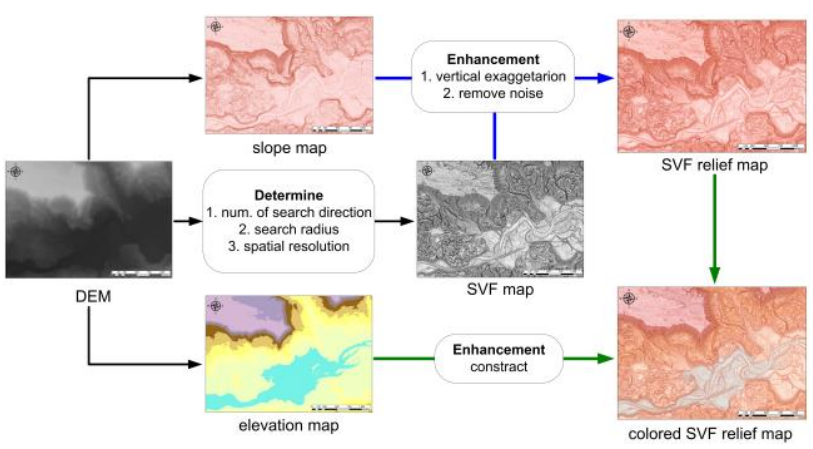

Figure 3. SVF relief map compilation procedure (Lo, 2017)

\subsection{Mapping criteria for deep-seated landslide}

Central Geological Survey in Taiwan categorizes landslide behavior into three main types based on slope movement classification by Varnes (1978): (1). debris slide (shallow landslide), (2). rockfall, and (3). rock slide(deep-seated landsldie). Generally speaking, deep-seated landsldie means a landslide process characterized by large-scale slope movement and deep-seated sliding plane. The surface of rupture for this slope movement usually appears beneath the bedrock, so that one can observe specific terrain features at different parts of landslide zonation (Fig. 4 and Tab.1; Central Geological Survey, 2010). The mapping principle in the study follows the definition of rock slide which was announced by CGS. For typical deepseated landslide in the field, a deep sliding plane, thick slope movement, and large-scale sediment volume often coexist and can be interpreted on the visualization map. The scale of landslide area even reaches more than 10 hectares, but the main body still preserves its integrity during sliding process. Regarding type of movement, deep-seated landslide comprises translational, rotational, and complex slides. Large-scale deepseated landslide is usually triggered by translational slide located on the dip slope in Taiwan - Tsaoling, and Chiufengershan for example. The ideal feature of the deepseated landslide is displayed in Fig. 4. All the characterization and the types which for extracting landslide feature from LiDAR derivatives are adopted into expert-based interpretation approach. Moreover, the corresponding criterion such as discordant vegetation for remote sensing on landslide feature is also taken into consideration (Tab. 1; Central Geological
Survey, 2010). Finally, the interpretation results obtained with this process will be verified and checked by three experts to reduce the misinterpretation.

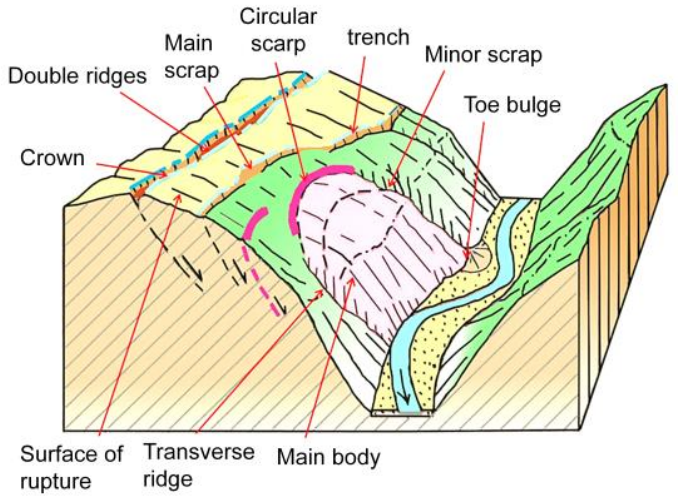

Figure 4. deep-seated landslide characteristics (modified from Takasuke, 2000)

\begin{tabular}{|c|c|}
\hline feature & description of deep-seated landslide \\
\hline $\begin{array}{l}\text { landslide } \\
\text { scarp }\end{array}$ & $\begin{array}{l}\text { horse-shoe shaped scarp or cliff. } \\
\text { fresh, open cracks that are evidence of } \\
\text { recent movement and indicate slipping or } \\
\text { tipping of the landslide body. } \\
\text { cracks often parallel to the edge of a scar. }\end{array}$ \\
\hline $\begin{array}{c}\text { landslide } \\
\text { body } \\
\text { (sliding } \\
\text { mass) }\end{array}$ & $\begin{array}{l}\text { shovel-shaped depression. } \\
\text { discordant natural vegetation on the } \\
\text { landslide boundary. } \\
\text { an upper part of the landslide mass shows } \\
\text { a hollow landform, and the lower part of } \\
\text { the landslide mass shows a topography } \\
\text { characteristic of a gentle slope or } \\
\text { tableland. }\end{array}$ \\
\hline $\begin{array}{l}\text { lateral } \\
\text { flank }\end{array}$ & $\begin{array}{l}\text { hydrological characteristics of two gullies } \\
\text { generated in the same source area. } \\
\text { echelon-type shear failure. }\end{array}$ \\
\hline slope toe & $\begin{array}{l}\text { bulging landform at the toe. } \\
\text { toe extends into the river channel, or } \\
\text { narrowing (curving) of the original } \\
\text { channel. } \\
\text { formation of a landslide dam upstream of } \\
\text { the slope toe. } \\
\text { radial cracking. }\end{array}$ \\
\hline
\end{tabular}

Table 1 Remote sensing interpretation characteristics for deepseated landslides (Central Geological Survey, 2010)

\section{RESULTS AND DISCUSSIONS}

\subsection{Deep-seated landslide mapping}

Based on the visualization SVF relief map, deep-seated landslides mapped using micro-topographic interpretation by experts in 2,764 map sheets (with 1:5000 scale) are completed. In the preliminary statistics, 619 landslide areas are mapped and are shown in Fig. 5(a)-(c) within the study area. An example of mapped deep-seated landslide feature is shown in Fig. 6. The mapped areas include the main scarp and landslide body. Fig. 7 indicates the statistical analysis of mapped landslide area for northern, central, and southern Taiwan. The mean area of each mapped target is approximately 10.83 ha, which satisfies with the "greater than 10 ha" criteria of classic deep-seated landslides by National Science and Technology Center for Disaster Reduction (NCDR). The mapping result shows most landslides are located around Hsuehshan Range, Central Range, 
and western foothills. Based on results of bedrock landslide mapping (Fig. 5) most bedrock landslides are distributed along the strike of the bedrock in western Taiwan, and most landslides are within the Central Range; a high elevation northeastsouthwest oriented range of mountains. Moreover, a few landslides are also clustered along the edge of the Datun volcano group and near the western foothills. The mapping results indicate that location of deep-seated landslide and geological structure (fault and fold) are highly relevant. The deep-seated landslides occurring within the study area are occurring within three primary lithological characters (Fig. 8): metamorphic rock $(53.0 \%)$, sedimentary rock $(45.6 \%)$ and pyrogenetic rock $(1.40 \%)$.
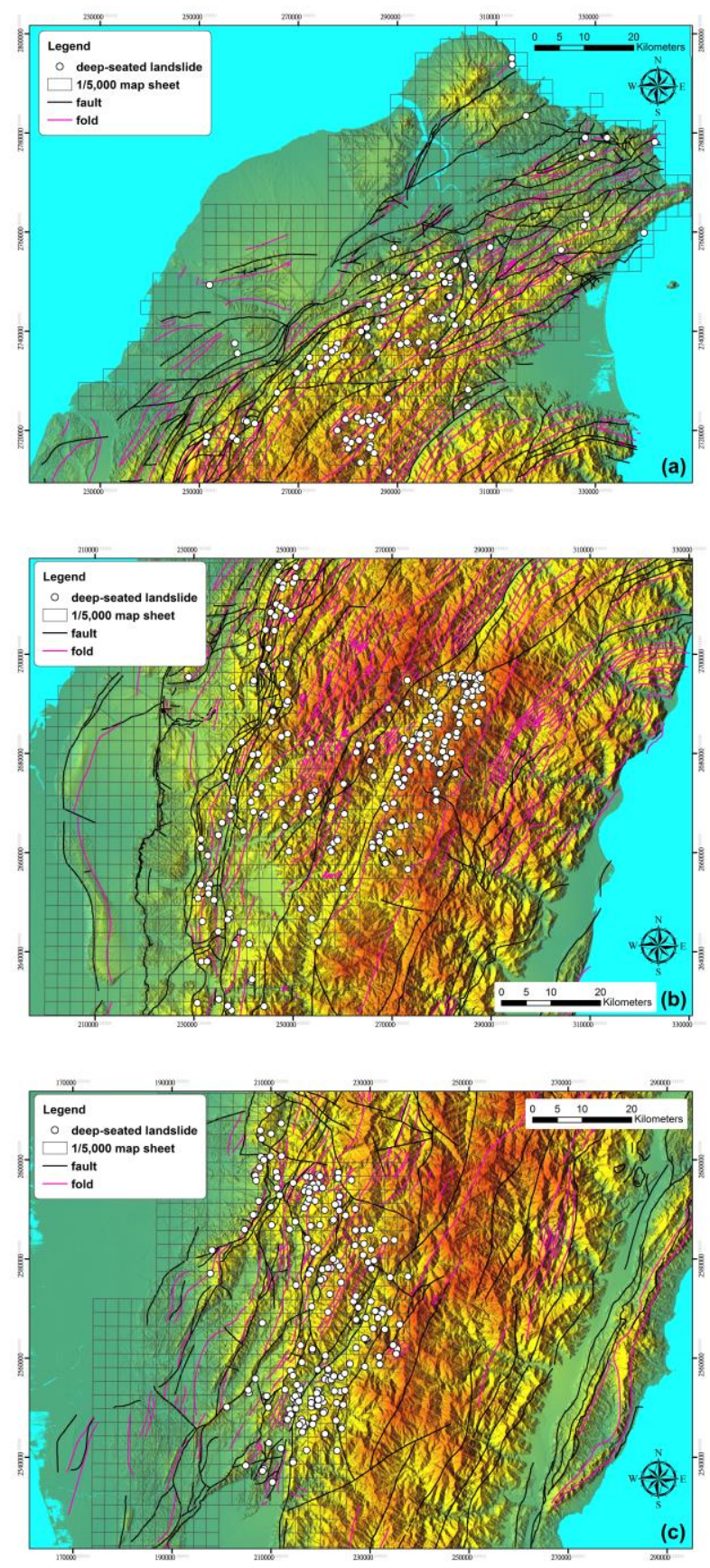

Figure 5. Deep-seated landslide mapping in the study area: (a)northern(122 landslides; 800 sheets), (b) central(235 landslides;1010 sheets), and (c) southern(262 landslides;954 sheets) Taiwan

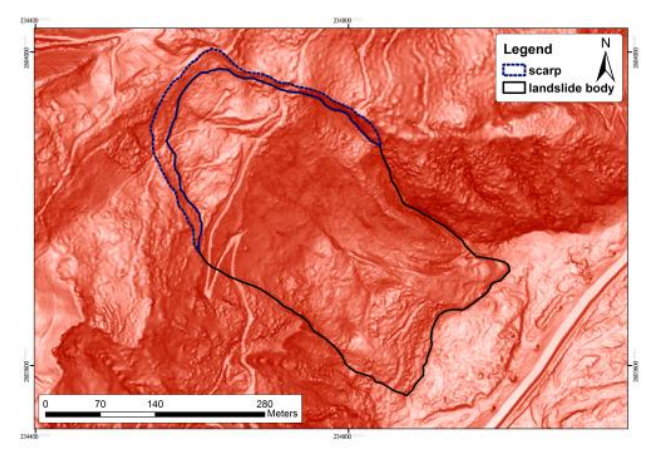

Figure 6. Illustration of main scarp and landslide body of the deep-seated landslide in central Taiwan

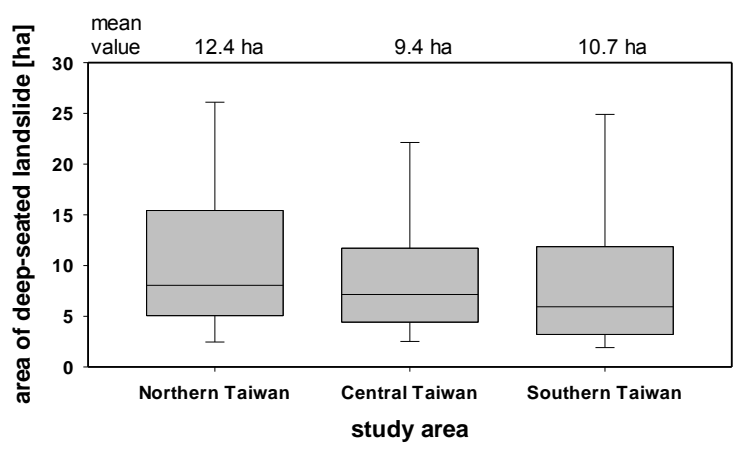

Figure 7. The box plot of deep-seated landslide area in different regions of Taiwan

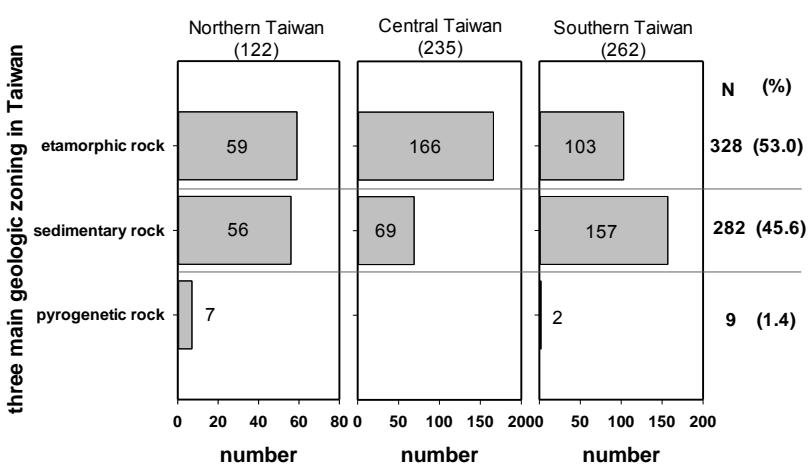

Figure 8 . The statistical analysis of deep-seated landslide on three primary three primary lithological characters.

\subsection{Topography characteristics}

In this section, topographic characteristics of the deep-seated landslides are examined and used to understand how the tectonic compressive forces that formed the mountains in the region also affect sliding behaviour and the failure mechanism. Usually, the partition of the deep-seated landslide is divided into hilltop (upper part of the watershed), main slope (slope divide to the foot of slope) and slope foot. The distribution of landslides is $19 \%, 56 \%$, and $25 \%$ respectively. Most landslides are found on the main slope. This finding demonstrates that most deep-seated landslides occur in a region of the slope that is susceptible to gravity-driven failures where secondary disasters are less likely to occur.

The runout distance of the landslide is primarily controlled by how open or restricted the topography is below the landslide. As shown in Fig 9, the landslide types served in the study area 
can be divided into complex landslides (279 cases; 44.6\%), rotational landslides (276 cases; $45.1 \%$ ), and translational landslides (64 cases; $10.3 \%$ ). Gravitational slope deformation is often a precursor to a deep-seated landslide because annual precipitation is exceptionally high and earthquakes are frequent in Taiwan; more importantly, the stream evolution of the stream network can trigger movement and may suggest that relative to slope processes, fluvial processes can act as the dominant control on landslide activity. As valleys rapidly incise as a consequence of high accumulated precipitation, not only are shallow landslides triggered, the slope of the original valley wall is increased, triggering a slope failure and development a topographic setting typical of most deep-seated landslides in a slope that was initially stable (Fig. 10).

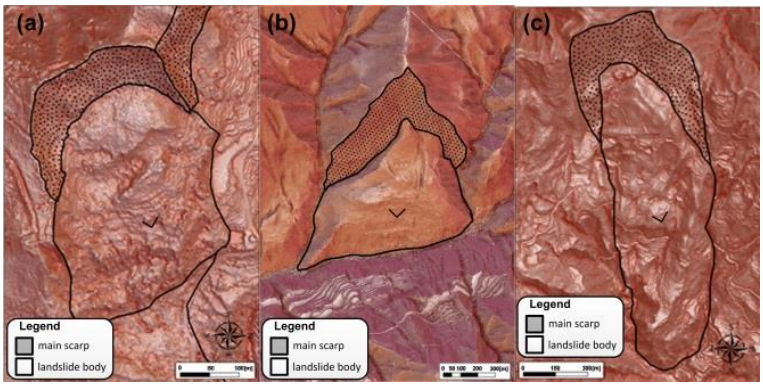

Figure 9. Three deep-seated landslide movement types in northern Taiwan: (a) rotational slide; (b) translational slide; (c) complex slide
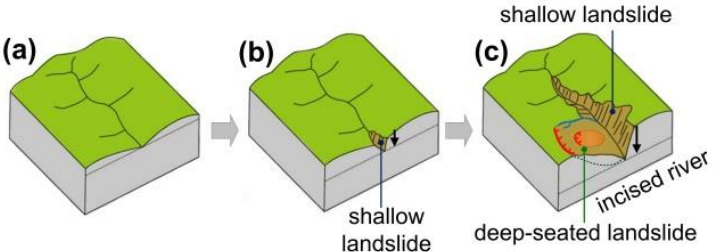

Figure 10. Illustration of linkage between slope processes and fluvial processes

\subsection{On-site investigation and validation}

To validate the credibility of landslide mapping results based on the interpretation of a high-resolution LiDAR DEMs, several landslides are randomly selected for field investigation. In the field validation, manual interpretation results are compared with field indicators of slope instability.

The Garden landslide was initiated at least 20 years ago and is one of the landslides selected for field investigation (Fig. 11). It is located in Wufong Township, Hsinchu County. The landslide is occurring in the Beiliao sandstone formation and Taulu shale formation on an anti-dip slope. A stream runs along the base of the slope towards the southeast. At the northeast edge of the stream, a reverse fault is mapped parallel to the stream. The Garden landslide is located on top of the fault. Several clear micro-topography features of the Garden landslide (Fig. 12) are indicative of the slope-movement including a discernible main scarp, main body, lateral flank and bulging toe. A debris slide and rock slide were triggered in this area during Typhoon Matsa 2005. Based on field investigation, the landslide is composed of two translational failing blocks. The blocks are labeled A and B, and both have the main scarp and main body. Based on the interpretation of UAV aerial photos, bedrock is exposed along a minor scarp near the ridge above the slide. The minor scarp also shows signs of rock fall and a talus deposit (Fig. 13a). Near the upper part of the toe of the main body, an SVF image reveals several well-developed gullies that appear to be triggering the formation of debris flows just down a slope of the kick-line.
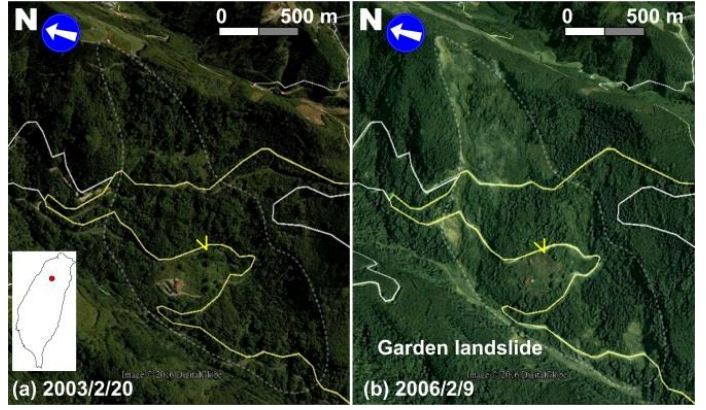

Figure 11. The remote sensing images of Garden Landslide before and after disaster (white dashed line is the landslide boundary; base map is from Google Earth)

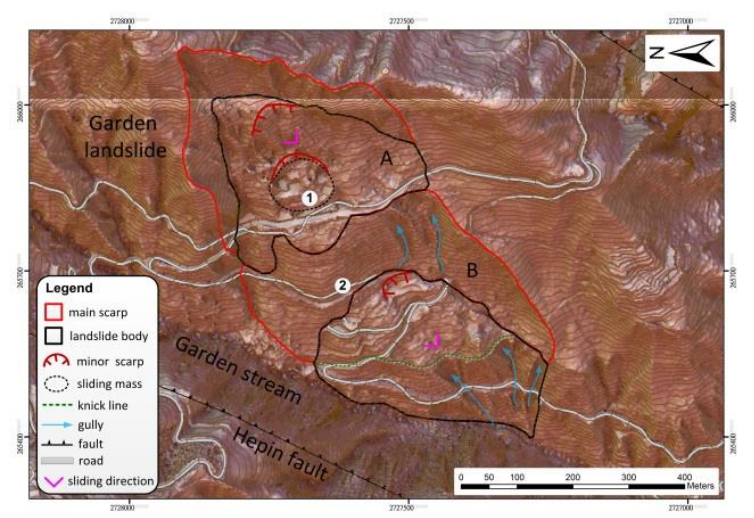

Figure 12. Micro-topography interpretation using an SVF relief map of the Garden landslide

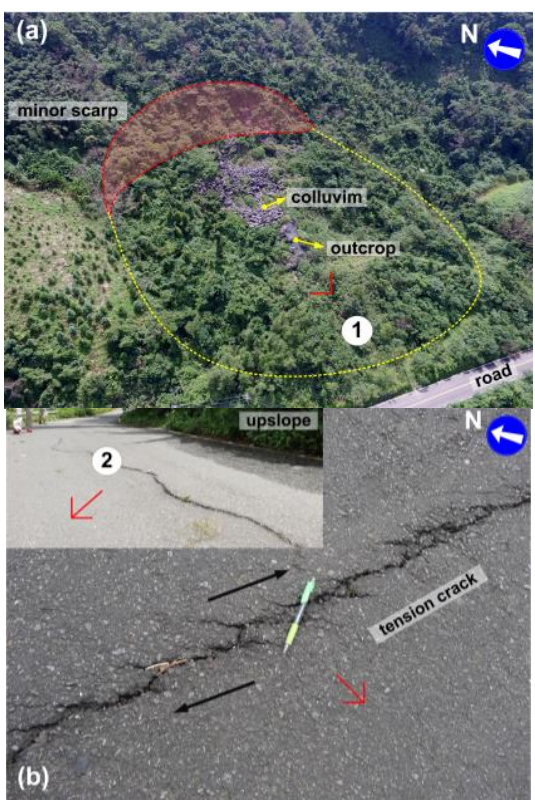

Figure 13. Topography feature in the study area: (a) talus deposit below the minor scarp; (b) echelon tension crack on bituminous pavement (the corresponding location is shown in Fig 12)

Through field investigation of failing block $\mathrm{B}$, both tension and shear cracks have been located on the road near the main body 
(Fig. 13b). The length of the tension cracks is roughly 30 meters and the sliding direction is in line with gravity (slope) and may indicate recent sliding. The activity of this area should be continuously monitored. Based on the geologic setting of the Garden landslide, the landslide is likely a rotational slide type (depth to the shear zone: $204 \mathrm{~m}$ ). The shear zone may be controlled by three planes of weakness in the bedrock including $(227 \%$ principal plane of weakness) $61 \% 51,69 \%$. The residual angle of internal friction along the failure plane is roughly 16.5 to 29 degrees.

These findings support the notion that SVF relief maps could efficiently enhance surface micro-topography and show gullies and fissures, that traditional shaded relief maps were unable. Additionally, two-dimensional maps can be used to create quasi-3D visual. These maps could aid geologic mapping and disaster prediction.

\subsection{Landslide susceptibility assessment}

Deep-seated landslide failure mechanism is affected by geologic setting, topography and hydrologic conditions. During the failure process and displacement, typical failure patterns include (1) regressive failure; (2) progressive failure; (3) translational failure. Of these failure types, the catastrophic landslide is the most dangerous to villages located near a landslide.

Regarding deep-seated landslides (Fig. 14), unless the slide occurs once as a single, catastrophic landslide, initial failure occurs near the crown or head of the landslide, and the unstable landslide mass remains parked on the failure plane. It is especially likely if topography below the slide is constrictive or the slope on which the slide is occurring is low. If no other triggering factors occur, a landslide can transition from an active to suspended or dormant state. Provided that the dormant landslide is affected by some other outside triggering factors such as rainfall or earthquakes, the landslide may become active again. Once active, the sliding mass can re-mobilize, stop and separate into a debris pile.

To further understand the mapped deep-seated landslides in the study area, potential active landslides and the reactivation potential of landslides is assessed using results from published documents, image analysis, topographic characteristics and monitoring records.

A potential reactivation rating is established for existing landslides using two metrics: topographic characteristics and recent landslide activities. Topographic characteristics include the micro-topographic characteristics of the landslide head, body, and toe.

The development of each landslide is evaluated using topographic conditions as well as several other indicators of potential instability (Table 2). Additionally, multi-temporal imagery available on Google-Earth is used to verify interpreted irregularities in the vegetation on the landslide. Recent landslide signs of activity are also checked with the 2001-2014 deepseated landslide inventory and confirm whether the recent movement has occurred. For landslides that already installed landslide monitoring systems, the mobilization history of the landslide is directly reviewed from the monitoring report.

Additionally, an expert-based approach is used to map potential landslides in northern Taiwan. An example of the expert-based approach susceptibility result is shown in Fig. 15. Results reveal that most landslides are located in a complicated geologic setting, such as fault and fold zones or areas of bedding contacts and regions of highly weathered rock and high dense stream networks. Moderate susceptibility landslides are located adjacent to rivers on dips slopes. High susceptibility landslides already show signs of landslide development such as perched areas of loose debris and steep scarps that have a higher potential to fail. Under intense rains, these would usually reactivate rapidly. If infrastructure or residential houses are located at the foot of such areas, these areas would require particular attention and prioritization for evacuation plannings.

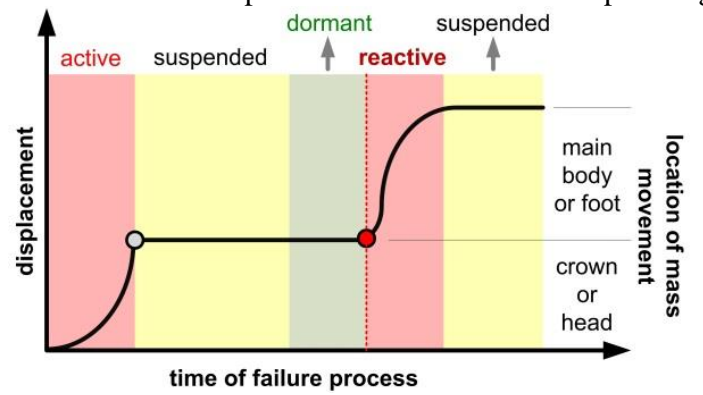

Figure 14. Displacement as a function of the failure process. Reactivation after suspension indicates a renewal of dormant deep-seated landslides (modified from Cruden and Varnes, 1996)

\begin{tabular}{|c|c|}
\hline Susceptibility & Terrain features \\
\hline Low & $\begin{array}{l}\text { Scarp and main body of landslide can be } \\
\text { identified and mapped. } \\
\text { Deep-seated gravitational slope deformation } \\
\text { is limited to the peak or ridgeline of the } \\
\text { slope (DSGSD). }\end{array}$ \\
\hline \multirow{4}{*}{ Moderate } & $\begin{array}{l}\text { crown and head: The scarp is rounded or } \\
\text { muted, suggesting the scarp is not fresh. } \\
\text { Additionally, the landslide body contains } \\
\text { two stream channels which originate from a } \\
\text { single location. Also, abnormal openings in } \\
\text { the forest canopy are discernible in images } \\
\text { of the landslide. }\end{array}$ \\
\hline & $\begin{array}{l}\text { main body: located on a dip slope, gullies } \\
\text { are well defined and dense, multiple areas of } \\
\text { debris, secondary scarps or reverse scarplets. }\end{array}$ \\
\hline & $\begin{array}{l}\text { foot and toe: A stream or road cuts across } \\
\text { the foot of a dip slope; the toe of the } \\
\text { landslide is less constricted than the head; } \\
\text { evidence of debris slides. }\end{array}$ \\
\hline & $\begin{array}{l}\text { recent observation: Observation of } \\
\text { movement has been recorded in the landslide } \\
\text { inventory within the last } 20 \text { years. }\end{array}$ \\
\hline \multirow{4}{*}{ High } & $\begin{array}{l}\text { crown and head: Tension cracks are located } \\
\text { upslope of the scarp and the scarp is fresh } \\
\text { and shows signs of recent formation. }\end{array}$ \\
\hline & $\begin{array}{l}\text { main body: The head is step-like, hummock } \\
\text { and the landslide mass is cracked and } \\
\text { fissured. The vegetative cover is disturbed. }\end{array}$ \\
\hline & $\begin{array}{l}\text { foot and toe: The foot and toe are adjacent } \\
\text { to high-energy, rapidly scouring reach of the } \\
\text { stream; the edge adjacent to the stream } \\
\text { shows signs of instability. }\end{array}$ \\
\hline & $\begin{array}{l}\text { recent observation: If a monitoring system } \\
\text { is installed, recent movement has been } \\
\text { recorded. }\end{array}$ \\
\hline
\end{tabular}

Table 2 Hillslope characteristics used for remote-sensing interpretation of deep-seated landslides 


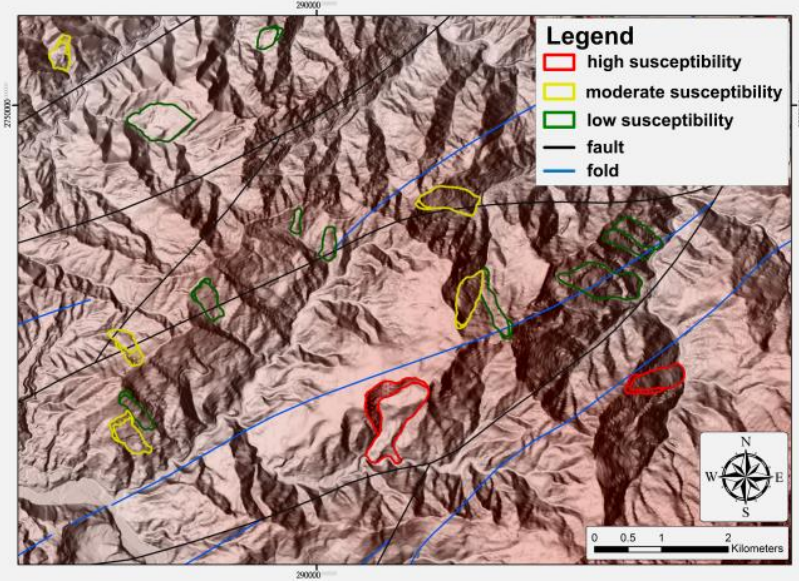

Figure 15. Results of an expert-based, deep-seated landslide susceptibility assessment

\section{CONCLUSION}

This study uses $1 \mathrm{~m}$ resolution LiDAR data to map deep-seated landslides in northern Taiwan. SVF relief maps are used to extract the micro-topography details and drainage characteristics of the study area. The scar and landslide body are interpreted manually, and in total, 619 landslides are mapped. The average area of the landslide is 10.83 ha. $53 \%$ of landslides are occurring in metamorphic rock. It suggests that the rotational failure $(45.1 \%)$ plays a dominant role in failure mechanism.

Interpretation of the SVF relief maps is enhanced and validated from bore-hole geologic data and field investigation. Once the competent authority gets the likely-hood of landslide recurrences from micro-topographic characteristics and monitoring data of recent activity, It may help making a proper decision prior landslide. The results of this work could be used for remediation, monitoring and disaster prevention studies. Moreover, future studies could be improved by combining interferometry synthetic aperture radar (InSAR) techniques with those applied in this study to regularly assess the stability and risk of landslide-prone areas that have high movement potential. In this way, the devastating effects of catastrophic landslides around mountain villages can be prevented and reduced in advance.

\section{ACKNOWLEDGEMENTS}

The authors would like to thank the Central Geological Survey, MOEA, Taiwan, for supporting this research financially and providing helpful comments on the research.

\section{REFERENCES}

Booth, A.M., Roering, J.J., Perron, J.T., 2009. Automated landslide mapping using spectral analysis and high-resolution topographic data: Puget Sound lowlands, Washington, and Portland Hills, Oregon. Geomorphology, 109, pp. 132-147.

Central geological survey, 2010. Geological hazard assessment and monitoring in mountain area. Central geological survey, MOEA, Taiwan (in Chinese).

Cruden, D.M., Varnes, D.J., 1996. Landslide types and processes, special report, transportation research board. National Academy of Sciences, 247, pp. 36-75.
Dilley, M., Chen, R.S., Deichmann, U., Lerner-Lam, A.L., Arnold, M., 2005. Natural disaster hotspots: a global risk analysis. World Bank Publications (ISBN 0-8213-5930-4).

Lee, C.F., Huang, C. M., Tsao, T.C., Wei, L.W., Huang, W. K., Cheng, C.T., Chi, C.C., 2016. Combining rainfall parameter and landslide susceptibility to forecast shallow landslide in Taiwan. Geotechnical Engineering Journal of the SEAGS \& AGSSEA, 47(2), pp. 72-82.

Lo, C.M., Lee, C.F., Keck, J., 2017. Application of sky view factor technique to the interpretation and reactivation assessment of landslide activity. Environmental Earth Science. 76,375 .

Martha, T.R., Kerle, N., Jetten, V., van Westen, C.J., Kumar, K. V., 2010. Detection of landslides by object-oriented image analysis. Geomorphology, 116, pp. 24-36.

Mayoral, A., Toumazet, J.P., Simon, F.S., Vautier, F., Peiry, J.L. 2017. The Highest Gradient Model: A new method for analytical assessment of the efficiency of LiDAR-derived visualization techniques for landform detection and mapping. Remote sensing, 9, 120.

Nonomura, A., Hasegawa, S., Dahal, R.K., Chiba, T., Tadono, T., 2013. A mapping method of deep-seated landslide susceptible slopes using digital elevation model. International Journal of Landslide and Environment. 1(1), pp. 67-68.

Petschko, H., Bell, R., Glade, T., 2016. Effectiveness of visually analyzing LiDAR DTM derivatives for earth and debris slide inventory mapping for statistical susceptibility modelling. Landslides, 13(5), pp.857-872.

Takasuke, S., 2000. Introduction of topographic map interpretation for construction engineer - Vol.3: terrace, hill, and mountain. Kokon Publisher. pp.811-815.

Van Den Eeckhaut, M., Kerle, N., Hervas, J., Supper, R., 2013. Mapping of landslides under dense vegetation cover using object-oriented analysis and LiDAR derivatives. Landslide Science and Practice, Margottini, C., (eds). 1, pp.103-109.

Varnes, D.J., 1978. Slope movement types and processes. In: Special Report 176: Landslides: Analysis and Control (Eds: Schuster R L \& Krizek R J). Transportation and Road Research Board, National Academy of Science, Washington D.C., pp.1133.

Yokoyama, R., Shirasawa, M., Pike, R.J., 2002. Visualizing topography by openness: A new application of image processing to digital elevation models. Photogrammetric Engineering and Remote Sensing, 68, pp.257-265.

Zakšek, K., Oštir, K., Kokalj, Ž., 2011. Sky-View factor as a relief visualization technique. Remote Sensing, 3, pp.398-415.

Razak, K.A., Straatsma, M.W., van Westen C.J., Malet, J.P., de Jong, S.M., 2011. Airbrone laser scanning of forested landslides characterization: Terrain model quality and visualization. Geomorphology, 126, pp.186-200. 